\title{
Variation in wing length in Eurasian natural populations of Drosophila melanogaster
}

\author{
ALEXANDRA G. IMASHEVA*, OLEG A. BUBLI \& OLEG E. LAZEBNY \\ Vavilov Institute of General Genetics, Gubkin Street 3, 117809 GSP-1, Moscow B-333, Russia
}

\begin{abstract}
A study of 16 natural populations of Drosophila melanogaster from Eastern Europe, the Caucasus and Central Asia has revealed a cline in wing length associated with geographical position of the populations. Wing length was shown to be positively correlated with temperature. The coefficient of variation in wing length was significantly different in town and orchard populations. The existence of a cline in wing length in the northern part of the species range and in the region where migration must be substantial suggests strong selection pressure acting in natural populations of $D$. melanogaster.
\end{abstract}

Keywords: clines, Drosophila melanogaster, genetic variation, natural populations, wing.

\section{Introduction}

Among natural populations of Drosophila melanogaster considerable genetic differentiation in quantitative characters has been demonstrated (Lemeunier et al., 1986; David \& Capy, 1988; Singh, 1989). Some morphological and physiological characters exhibit latitudinal clines in this species. One of them is a welldocumented cline for numerous characters, including wing length, which extends from France to tropical Africa (David \& Bocquet, 1975a, b; Allemand \& David, 1976; David et al., 1977; Cohet \& David, 1980; Cohet et al., 1980). Another cline for wing length and abdominal bristle number has been reported in populations of the east coast of the U.S.A. (Coyne \& Beecham, 1987).

In this paper we present evidence for clinal variation in wing length in wild populations of $D$. melanogaster that are located in the Palearctic zoogeographic region, i.e. in the northern part of the species range. The existence of three parallel clines in wing length is a strong argument for an adaptive significance of variation in this character.

\section{Materials and methods}

The flies were collected in 16 localities of Eastern Europe, the Caucasus region and Central Asia (Fig. 1). The list of collection sites, their latitudes, longitudes,

\footnotetext{
${ }^{*}$ Correspondence.
}

temperatures and dates of collection are given in Table 1. Since the size of the wing in natural populations of Drosophila is subject to seasonal changes (see e.g. Tantawy \& Mallah, 1961), we have restricted the sampling period to the two hottest summer months (from mid-July to early September) when D. melanogaster is most abundant in the surveyed region. Collections were made in the large commercial apricot or apple orchards situated in rural areas ('orchard' samples), or on fruit stalls in city markets and in garbage bins outside wineries or fruit-processing factories ('town' samples). About 30 isofemale lines were started for each of the localities with females taken from the sample at random. After oviposition the females of the parental generation were removed from vials and their left wings were measured.

From the progeny of each isofemale line five pairs of flies were put into a separate vial, left for three days to lay eggs and discarded. To make the population density for the analysed flies uniform for all cultures, 60 eggs from each vial were removed and placed in a vial with fresh medium. After emergence of adults they were collected, five females chosen at random, their left wings removed, mounted on a slide and measured with an ocular micrometer. This gave a total sample size of about 150 wings per locality. The length of the wing was measured as the distance from the outer margin of the anterior crossvein along the third longitudinal vein to the wing tip and given in micrometer units (1 unit $=0.014 \mathrm{~mm}$ ).

All cultures were kept on standard Drosophila medium at $25^{\circ} \mathrm{C}$, the physiologically optimal tempera- 


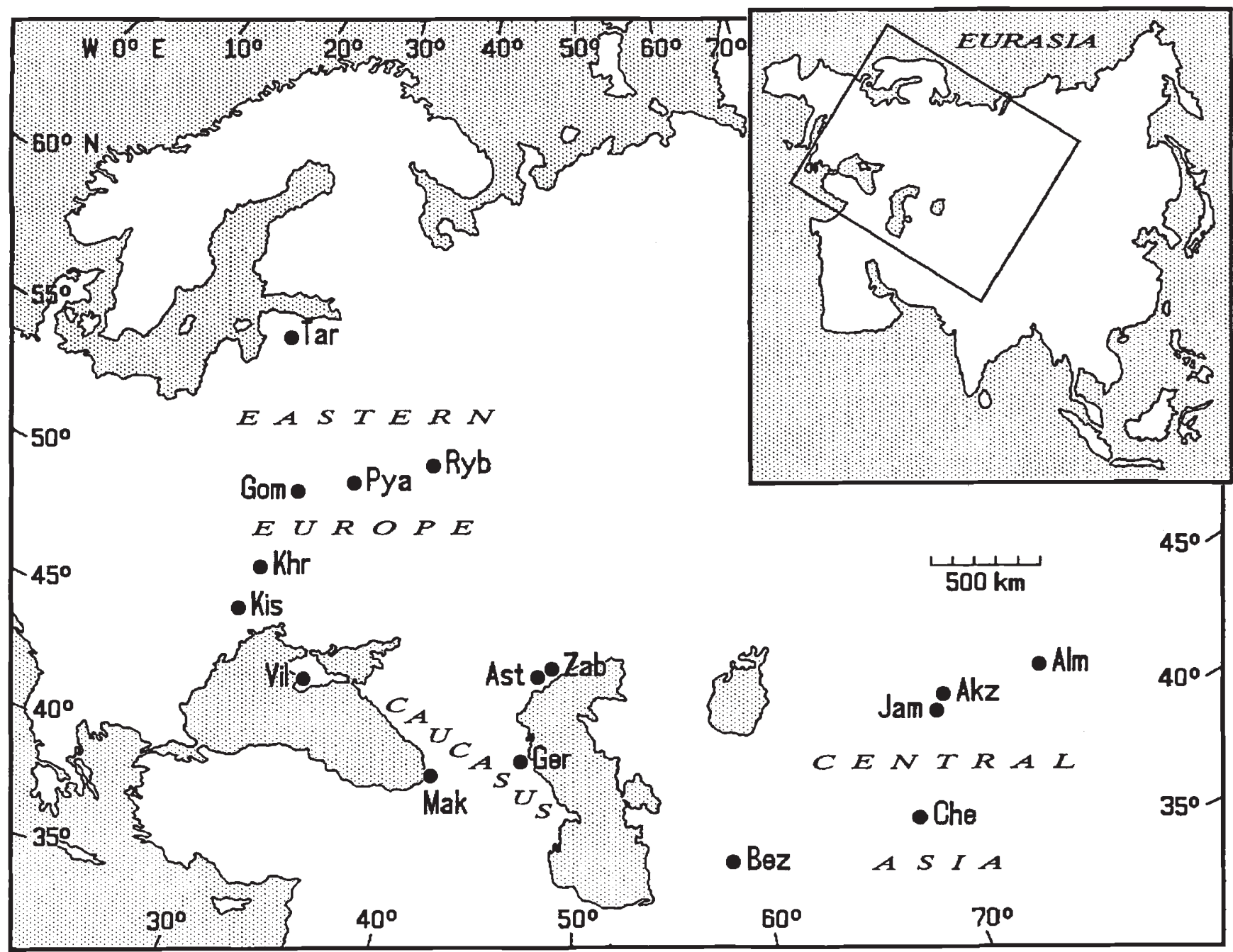

Fig. 1 Collection sites. For explanation, see Table 1.

Table 1 Populations of Drosophila melanogaster used in this study

\begin{tabular}{lccccccc}
\hline Locality & Country & Latitude $(\mathrm{N})$ & Longitude $(\mathrm{E})$ & $T_{\text {max }} \dagger$ & $T_{\text {year }} \ddagger$ & Habitat & Time of sampling \\
\hline Tartu (Tar) & Estonia & $58^{\circ} 23^{\prime}$ & $26^{\circ} 44^{\prime}$ & $17.4^{\circ}$ & $5.0^{\circ}$ & Town & Aug. 1989 \\
Rybnoe (Ryb) & Russia & $54^{\circ} 43^{\prime}$ & $39^{\circ} 30^{\prime}$ & $18.4^{\circ}$ & $3.8^{\circ}$ & Orchard & Jul. 1989 \\
Pyany Rog(Pya) & Russia & $52^{\circ} 54^{\prime}$ & $33^{\circ} 35^{\prime}$ & $19.0^{\circ}$ & $5.3^{\circ}$ & Orchard & Aug. 1990 \\
Gomel (Gom) & Byelorussia & $52^{\circ} 26^{\prime}$ & $30^{\circ} 59^{\prime}$ & $18.5^{\circ}$ & $6.1^{\circ}$ & Town & Sep. 1991 \\
Khristinovka (Khr) & Ukraine & $48^{\circ} 49^{\prime}$ & $29^{\circ} 58^{\prime}$ & $19.2^{\circ}$ & $7.3^{\circ}$ & Orchard & Aug. 1991 \\
Kishinev (Kis) & Moldavia & $47^{\circ} 01^{\prime}$ & $28^{\circ} 50^{\prime}$ & $21.7^{\circ}$ & $9.5^{\circ}$ & Orchard & Aug. 1990 \\
Zabuzan (Zab) & Russia & $46^{\circ} 32^{\prime}$ & $48^{\circ} 18^{\prime}$ & $25.5^{\circ}$ & $9.4^{\circ}$ & Orchard & Sep. 1991 \\
Astrakhan(Ast) & Russia & $46^{\circ} 22^{\prime}$ & $48^{\circ} 03^{\prime}$ & $25.3^{\circ}$ & $9.4^{\circ}$ & Town & Sep. 1990 \\
Vilino(Vil) & Ukraine & $44^{\circ} 52^{\prime}$ & $33^{\circ} 36^{\prime}$ & $23.0^{\circ}$ & $11.3^{\circ}$ & Orchard & Jul. 1989 \\
Alma-Ata(Alm) & Kazakhstan & $43^{\circ} 16^{\prime}$ & $77^{\circ} 57^{\prime}$ & $23.4^{\circ}$ & $8.7^{\circ}$ & Town & Jul. 1991 \\
Akzhar (Akz) & Kazakhstan & $43^{\circ} 07^{\prime}$ & $71^{\circ} 38^{\prime}$ & $23.6^{\circ}$ & $9.1^{\circ}$ & Orchard & Jul. 1992 \\
Jambul(Jam) & Kazakhstan & $42^{\circ} 54^{\prime}$ & $71^{\circ} 23^{\prime}$ & $23.6^{\circ}$ & $9.1^{\circ}$ & Town & Aug. 1991 \\
Gergebil (Ger) & Russia & $42^{\circ} 31^{\prime}$ & $47^{\circ} 04^{\prime}$ & $18.3^{\circ}$ & $7.2^{\circ}$ & Orchard & Jul. 1992 \\
Makhinjauri (Mak) & Georgia & $41^{\circ} 40^{\prime}$ & $41^{\circ} 42^{\prime}$ & $22.0^{\circ}$ & $14.5^{\circ}$ & Orchard & Jul. 1990 \\
Cheptura (Che) & Tajikistan & $38^{\circ} 32^{\prime}$ & $68^{\circ} 21^{\prime}$ & $27.9^{\circ}$ & $14.2^{\circ}$ & Town & Sep. 1991 \\
Bezmein (Bez) & Turkmenistan & $38^{\circ} 03^{\prime}$ & $58^{\circ} 11^{\prime}$ & $30.3^{\circ}$ & $16.4^{\circ}$ & Town & Aug. 1992 \\
\hline
\end{tabular}

†Average temperature of the hottest calendar month.

$\ddagger$ Average year temperature. 
ture for this species (David et al., 1983). Although in the present study there was not much danger of confusing $D$. melanogaster with its sibling species $D$. simulans, since the latter is rarely found in the region covered by the survey (Imasheva, A. G. et al., unpublished data), all $F_{1}$ cultures were checked by examining males; no $D$. simulans individuals were found.

Temperature data for weather stations adjacent to collection sites were obtained from the Committee for Meteorology of the Russian Federation (Rosgidromet). The distance from collection sites to weather stations was in all cases less than $50 \mathrm{~km}$ (20 km on average). Two temperature variables were used: average year temperature $\left(T_{\text {year }}\right)$ and average temperature of the hottest calendar month $\left(T_{\max }\right.$; July for all localities except Makhinjauri for which it was August); for both parameters, 10-year averages (1980-1990) were used. Temperature values are listed in Table 1. 4.1).

Statistical analysis was done using SYSTAT (version

\section{Results}

In Table 2 average wing lengths and coefficients of variation are given for wild-caught $(\mathrm{P})$ and laboratoryreared $F_{2}$ flies from the 16 studied populations (to eliminate the dependence of variance on the mean value of wing length we have used coefficients of variation rather than variance as the measure of withinpopulation variation). The results of the nested
ANOVA for laboratory-reared flies are presented in Table 3 .

Variation among populations is highly significant, showing that populations are geographically differentiated according to wing length. The isofemale lines also contribute significantly to the variation. This is to be expected since genetic determination of wing length in Drosophila is a firmly established fact, and heritability of this character estimated in laboratory conditions is high, varying from 0.2 to 0.6 (see e.g Robertson \& Reeve, 1952; Reeve \& Robertson, 1953; Latter \& Robertson, 1962).

The data in Table 2 clearly show that the average wing length in the populations under study decreases from north to south and from west to east, thus forming a cline. This is confirmed by regression analysis, which demonstrated a significant relationship between wing length and latitude and longitude of populations (Fig. 2a, b). Regression slopes were significantly different from zero both in wild-caught parents (latitude: $b=0.782, P<0.01, r^{2}=0.498$; longitude: $\left.b=-0.294, P<0.001, r^{2}=0.618\right)$ and in laboratory-reared offspring (latitude: $b=0.188, P<0.001$, $r^{2}=0.595$; longitude: $\left.b=-0.062, P<0.001, r^{2}=0.574\right)$. As can be seen from Fig. 2, the regression slope is steeper in the wild-caught flies compared with the laboratory-reared ones, which must be due to the fact that in nature flies live in a variety of habitats while in laboratory cultures environmental conditions are uniform.

No significant association with altitude was found for either wild-caught or laboratory-reared flies (the

Table 2 Mean wing length $(\bar{x})$ and coefficient of variation $(\mathrm{CV})$ in 16 Eurasian populations of Drosophila melanogaster

\begin{tabular}{|c|c|c|c|c|c|c|c|c|c|}
\hline \multirow[b]{2}{*}{ Population } & \multirow[b]{2}{*}{ Habitat } & \multicolumn{4}{|c|}{ Wild-caught flies $(\mathrm{P})$} & \multicolumn{4}{|c|}{ Laboratory-reared flies $\left(F_{2}\right)$} \\
\hline & & $n$ & $\bar{x}$ & S.E. & $\mathrm{CV}(\%)$ & $n$ & $\bar{x}$ & S.E. & $\mathrm{CV}(\%)$ \\
\hline Tartu & Town & 55 & 116.82 & 0.70 & 4.44 & 150 & 114.03 & 0.30 & 3.26 \\
\hline Rybnoe & Orchard & 53 & 115.53 & 0.95 & 5.98 & 150 & 113.50 & 0.33 & 3.53 \\
\hline Pyany Rog & Orchard & 50 & 119.74 & 0.61 & 3.60 & 140 & 112.86 & 0.23 & 2.43 \\
\hline Gomel & Town & 60 & 116.85 & 0.95 & 6.32 & 150 & 113.15 & 0.28 & 3.02 \\
\hline Khristinovka & Orchard & 60 & 116.63 & 0.99 & 6.57 & 150 & 114.55 & 0.23 & 2.46 \\
\hline Kishinev & Orchard & 45 & 114.64 & 1.07 & 6.24 & 150 & 112.68 & 0.22 & 2.37 \\
\hline Zabuzan & Orchard & 55 & 102.93 & 1.03 & 7.44 & 150 & 111.45 & 0.24 & 2.67 \\
\hline Astrakhan & Town & 33 & 113.64 & 0.55 & 2.77 & 150 & 112.02 & 0.28 & 3.07 \\
\hline Vilino & Orchard & 53 & 110.81 & 1.30 & 8.57 & 150 & 111.20 & 0.28 & 3.11 \\
\hline Alma-Ata & Town & 60 & 105.07 & 1.32 & 9.75 & 150 & 111.49 & 0.25 & 2.80 \\
\hline Akzhar & Orchard & 60 & 106.73 & 0.82 & 5.94 & 150 & 110.29 & 0.22 & 2.45 \\
\hline Jambul & Town & 55 & 98.24 & 1.41 & 10.65 & 135 & 111.31 & 0.30 & 3.12 \\
\hline Gergebil & Orchard & 29 & 106.38 & 0.99 & 5.00 & 145 & 112.86 & 0.23 & 2.47 \\
\hline Makhinjauri & Orchard & 27 & 114.00 & 1.68 & 7.67 & 135 & 112.66 & 0.20 & 2.09 \\
\hline Cheptura & Town & 60 & 108.45 & 1.20 & 8.57 & 150 & 109.85 & 0.41 & 4.56 \\
\hline Bezmein & Town & 50 & 101.78 & 0.87 & 6.02 & 150 & 109.94 & 0.29 & 3.25 \\
\hline
\end{tabular}


results of regression analysis are not presented), probably because none of the populations under study was located higher than $800 \mathrm{~m}$ above sea level, so altitudinal climatic differences were probably not sufficient to cause population differentiation.

The regression analysis on temperature (Fig. 2c, d) has shown strong association between the wing length

Table 3 Nested ANOva of wing length for Eurasian populations of Drosophila melanogaster

\begin{tabular}{lrrrc}
\hline Source of variation & d.f. & \multicolumn{1}{c}{ SS } & \multicolumn{1}{c}{ MS } & $F$ \\
\hline Among localities & 15 & 4445.83 & 296.39 & $9.99^{* * *}$ \\
Among lines & 455 & 13505.33 & 29.68 & $4.47^{* * *}$ \\
Error & 1884 & 12498.80 & 6.63 & \\
\hline
\end{tabular}

$* * * P<0.001$ of laboratory-reared populations and the hottest calendar month temperature, $T_{\max }(b=-0.330, P<0.001$, $r^{2}=0.769$ ), as well as average year temperature, $T_{\text {year }}$ $\left(b=-0.281, \quad P<0.01 \quad r^{2}=0.502\right)$. In wild-caught populations, this relationship was statistically significant for $T_{\max }\left(b=-1.112, P<0.01, r^{2}=0.422\right)$ and non-significant for $T_{\text {year }}(b=-0.857, \quad P>0.05$, $r^{2}=0.225$ )

In order to determine the relative magnitudes of the contributions of the variables under study (latitude, longitude and the two temperature parameters) to the wing length variation, we performed multiple regression analysis, the results of which are presented in Table 4. Only the regression on $T_{\max }$ in laboratoryreared flies was significant. The association between the variables and wing length was tighter in laboratoryreared flies where it accounted for 84 per cent of between-population variation.
Fig. 2 The relationship of wing length in wild-caught (open circles) and laboratory-reared (solid circles) populations of Drosophila melanogaster to latitude (a), longitude (b), temperature of the hottest calendar month (c) and average year temperature (d). Regression lines: dotted, wild-caught; solid, laboratory-reared.
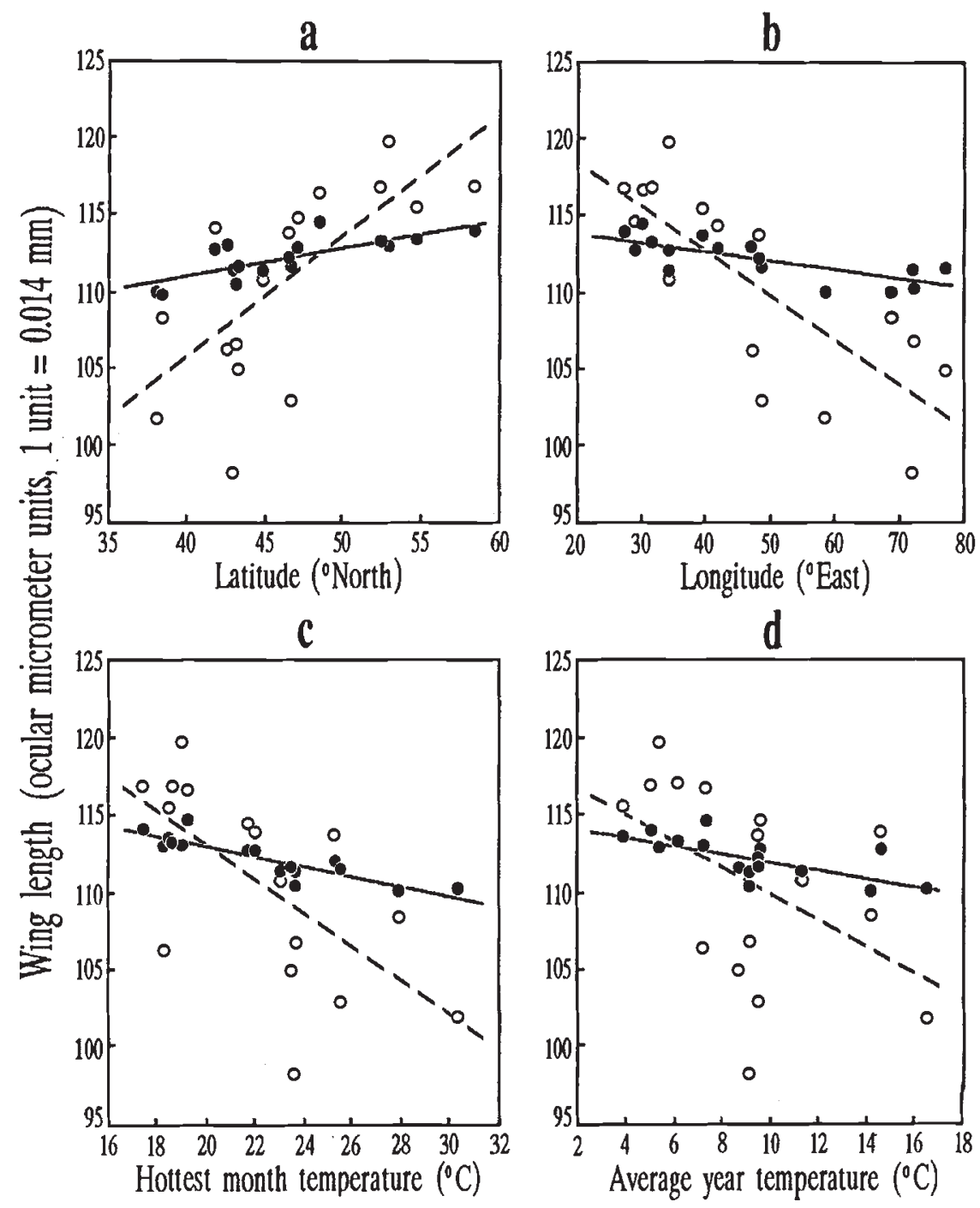
Table 4 Linear multiple regression of wing length on geographical and temperature variables

\begin{tabular}{|c|c|c|c|c|}
\hline \multirow[b]{2}{*}{ Variables } & \multicolumn{2}{|c|}{ Wild-caught flies $(\mathbf{P})$} & \multicolumn{2}{|c|}{$\begin{array}{l}\text { Laboratory-reared } \\
\text { flies }\left(\mathrm{F}_{2}\right)\end{array}$} \\
\hline & $b$ & $R^{2}$ & $b$ & $R^{2}$ \\
\hline Latitude & 0.638 & & 0.019 & \\
\hline Longitude & -0.127 & $0.700^{* *}$ & -0.026 & $0.843^{* * *}$ \\
\hline$T_{\max } \dagger$ & -0.663 & & $-0.232^{*}$ & \\
\hline$T_{\text {yeart }} \ddagger$ & 0.851 & & -0.001 & \\
\hline
\end{tabular}

$b$, partial regression coefficient; $R^{2}$, coefficient of determination.

${ }^{*} P<0.05,{ }^{* *} P<0.01,{ }^{* * *} P<0.001$.

$\dagger$ Average temperature of the hottest calendar month.

$\ddagger$ Average year temperature.

A comparison of populations occupying different habitats showed that average wing length was not influenced by habitat either in wild-caught or in laboratory-reared flies. The same was shown for variation in wild-caught flies. In laboratory-reared flies, however, coefficients of variation were dependent on the habitat, being on average higher in populations sampled in fruit-processing plants and in markets, and lower in those sampled in fruit orchards. The difference between them was significant as shown by the KruskalWallis test (Table 5).

\section{Discussion}

Geographical clines similar to the one we have revealed theoretically could result from two causes (Endler, 1977). One is the pressure of natural selection associated with some climatic variable, which in turn depends on the geographical position of the population. The alternative explanation is the interaction of genetic drift and migration. At present there is little doubt that latitudinal clines in wing length - and in body size in general - in Drosophila are caused by selection. The cline demonstrated in the present study (as has been) is the third reported in D. melanogaster. Similiar clines more or less well documented have been demonstrated for several other Drosophila species: $D$. robusta (Stalker \& Carson, 1947), D. subobscura (Prevosti, 1955; Misra \& Reeve, 1964; Pfriem, 1983), D. virilis (David \& Kitagawa, 1982) and D. simulans (Hyytia et al., 1985).

In all of them there was positive correlation of wing size with latitude: the wings in the northern populations were larger. It is extremely unlikely that such a number of parallel clines can result from chance events.
Table 5 Kruskal-Wallis test for differences in mean wing length $(\bar{x})$ and coefficient of variation $(\mathrm{CV})$ of wild-caught $(\mathrm{P})$ and laboratory-reared $\left(\mathrm{F}_{2}\right)$ flies from different habitats

\begin{tabular}{|c|c|c|c|c|c|}
\hline \multirow[b]{2}{*}{ Habitat } & \multirow{2}{*}{$\begin{array}{l}\text { Sample } \\
\text { size }\end{array}$} & \multicolumn{2}{|c|}{$\begin{array}{l}\text { Average rank } \\
\quad \text { of } \bar{x}\end{array}$} & \multicolumn{2}{|c|}{$\begin{array}{c}\text { Average rank } \\
\text { of } \mathrm{CV}\end{array}$} \\
\hline & & $P$ & $\mathbf{F}_{2}$ & $P$ & $F_{2}$ \\
\hline Orchards & 9 & 9.33 & 9.44 & 7.94 & 6.00 \\
\hline Towns & 7 & 7.43 & 7.29 & 9.21 & 11.71 \\
\hline Test statistic, $H$ & & 0.63 & 0.81 & 0.28 & $5.67^{*}$ \\
\hline
\end{tabular}

$* P<0.05$.

The selective factor that forms these clines is almost certainly temperature. Whenever it is colder flies' wings are larger; this is evident in seasonal variation (Tantawy \& Mallah, 1961) and in association with altitude (Stalker \& Carson, 1948; Louis et al., 1982). This view is also confirmed by laboratory selection experiments where flies kept at a colder temperature for many generations eventually acquire bigger wings (Anderson, 1966, 1973; Powell, 1974).

In our experiment, wing length showed significant correlation with both temperature parameters used in the analysis, but the association with the temperature of the hottest month, $T_{\max }$, was much stronger than that with the average year temperature, $T_{\text {year }}$. In view of the interpretation involving selection, these results seem quite reasonable. $T_{\max }$ is an indicator of the temperature of the warm season when selection must operate most strongly, since it is at this time that $D$. melanogaster populations are most abundant and live outdoors. On the other hand, the $T_{\text {year }}$ parameter includes temperatures of colder months when in northern regions $D$. melanogaster overwinters indoors and is not subjected to factors of the external environment.

Though temperature seems to be generally accepted as a selective agent in this case, the actual mechanism of selection is not yet understood. Since wing size is positively correlated with body size (Reeve \& Robertson, 1953), it is presumed that selection works directly on body size. Bergmann's rule (body size increases with latitude) is usually invoked though it does not really clarify the issue, since in poikilothermic animals like Drosophila it is not clear how it works. A review of possible mechanisms of selection for size by temperature is given by Coyne and Beecham (1987). One hypothetical explanation discussed by them is selection connected with developmental time of flies.

Since at higher temperatures flies develop faster and are smaller, selection favouring rapid development 
could lead to smaller fly size. This hypothesis is confirmed by the results of Cohet et al. (1980) who demonstrated faster developmental rate for African populations of $D$. melanogaster compared with European ones. However, our preliminary experiments have not shown any differences between time of development of Central Asian and European populations (Bubli \& Imasheva, 1994). There is also a possibility that selection might act on wing length in a way connected with efficiency of flight (Stalker, 1980) or with thermoregulation via the wing surface (Kingsolver \& Koehl, 1985).

The two previously reported clines for $D$. melanogaster (David et al., 1977; Coyne \& Beecham, 1987) concerned populations inhabiting much more southern areas with climatic conditions ranging from mild to hot. Our survey includes localities from as far north as Estonia, which is probably the extreme northern edge of the range of the species (David \& Capy, 1988). The fact that a stable cline exists so far north and in such drastic temperature conditions supports the view that populations of $D$. melaongaster living there are not a result of frequent (each season) recolonization from warmer regions, but are continuously living and reproducing there.

A noteworthy fact is the existence of a cline over a rather small geographical distance in a cosmopolitan domestic species like D. melanogaster. Even supposing that by active migration $D$. melanogaster does not cover hundreds of miles (though there is evidence to the contrary: see Coyne et al., 1982; Coyne \& Milstead, 1987; Coyne et al., 1987), the passive transportation (with food products, etc.) must be substantial, especially in the region in question, where rotten fruits and vegetables are often transported by train in mass quantities. The existence of a cline in such conditions proves the existence of strong selection pressure.

The regressions of wing length on geographical and temperature parameters in wild-caught flies were stronger than those in laboratory ones, i.e. the clines in the wild-caught flies were much steeper. This is to be expected because of the effect of local temperature on individual development. Flies from northern parts of the range have an additional source of variation since they develop in a cold habitat which causes larger body size (and vice versa for flies from southern parts of the range). Note, though, that in $D$. melanogaster populations of the east coast of North America, the opposite trend was found: the latitudinal cline in wing length was shallower in wild-caught flies compared with their laboratory progeny (Coyne \& Beecham, 1987).

As expected, phenotypic variation of wing length was much higher in wild-caught than in laboratoryreared flies. The ratio of the variances of wild-caught to laboratory-reared flies was about 12 , which is close to a previous estimate of 15 for a French natural population of D. melanogaster (David, 1979). The low estimate of this ratio reported by Coyne \& Beecham (1987) for populations of the east coast of North America (between 1.5 and 3, depending on the temperatures at which laboratory flies were raised) seems puzzling as it is not obvious what differences could exist between the ecology of the sampling sites in their case and ours.

One further point to consider is the difference in variation in populations occupying different habitats. Although mean wing length did not differ in this case, the coefficient of variation was higher in populations sampled in the town areas (wineries, fruit-processing factories and markets) compared with large gardens situated in the rural areas. This might be due to a greater genetic heterogeneity of the town samples, which could consist of a mixture of flies transported there from different neighbouring localities, or to the fact that the town habitats are less uniform.

\section{Acknowledgements}

We thank Jerry Coyne, Boris Kalabushkin, Yuri Dubrova and anonymous reviewers for critical comments on the earlier version of the manuscript. The work is supported by a research grant from the Programme 'Frontiers in Genetics' of the Russian Federation.

\section{References}

ALLEMAND, R. AND DAVID, J. R. 1976. The circadian rhythm of oviposition in Drosophila melanogaster: A genetic latitudinal cline in wild populations. Experientia, 32, 1403-1404.

ANDERSON, w. w. 1966. Genetic divergence in M. Vetukhiv's experimental populations of Drosophila pseudoobscura. 3. Divergence in body size. Genet. Res., 7, 255-266.

ANDERSON, w. w. 1973. Genetic divergence among experimental populations of Drosophila pseudoobscura kept at different temperatures. Evolution, 27, 278-294.

BUBLI, O. A. AND IMASHEVA, A. G. 1994. Genetic differentiation of three quantitative traits in Drosophila melanogaster natural populations of Eastern Europe and Central Asia. Russian J. Genet., 30, 57-63.

COHET, Y. AND DAVID, J. R. 1980. Geographic divergence and sexual behaviour: Comparison of mating systems in French and Afrotropical populations of Drosophila melanogaster. Genetica, 54, 161-165.

COHET, Y., vOUIDIBIO, J. AND DAVID, J. R. 1980. Thermal tolerance and geographic distribution: A comparison of cosmopolitan and tropical endemic Drosophila species. J. Therm. Biol., 5, 69-74. 
COYNE, J. A. AND BEECHAM, E. 1987. Heritability of two morphological characters within and among natural populations of Drosophila melanogaster. Genetics, 117, 727-737.

COYNE, J. A. AND MILSTEAD, B. 1987. Long-distance migration of Drosophila. 3. Dispersal of D. melanogaster alleles from a Maryland orchard. Am. Nat., 130, 70-82.

COYNE, J. A., BOUSSY, J. A., PROUT, T., BRYANT, S. N., JONES, J. S. AND MOORE, J. A. 1982. Long-distance migration of Drosophila. Am. Nat., 119, 589-595.

COYNE, J. A., BRYANT, S. N. AND TURELLI, M. 1987. Long-distance migration of Drosophila. 2. Presence in desolate sites and dispersal near a desert oasis. Am. Nat., 129, 847-861.

DAVID, J. R. 1979. Utilization of morphological traits for the analysis of genetic variability in wild populations. Aquilo Ser. Zool., 20, 41-61.

DAVID, J. R. AND BOCQUET, C. 1975a. Evolution in a cosmopolitan species: genetic latitudinal clines in Drosophila melanogaster wild populations. Experientia, 31, 164-166.

DAVID, J. R. AND BOCQUET, C. 1975b. Similarities and differences in latitudinal adaptation of two Drosophila sibling species. Nature, 257, 588-590.

DAVID, I. R. AND KITAGAWA, O. 1982. Possible similarities in ethanol tolerance and latitudinal variations between Drosophila virilis and D. melanogaster. Jpn J. Genet., 57, 89-95.

DAvID, J. R. AND CAPY, P. 1988. Genetic variation of Drosophila melanogaster natural populations. Trends Genet., 4, $106-111$.

DAVID, J., BOCQUET, C. AND DE SCHEEMAEKER-LOUIS, M. 1977. Genetic latitudinal adaptation of Drosophila melanogaster: new discriminative biometrical traits between European and equatorial African populations. Genet. Res., 30, 247-255.

DAVID, J. R., ALLEMAND, R., VAN HERREWEGE, J. AND COHET, Y. 1983. Ecophysiology: abiotic factors. In: Ashburner, M., Carson, H. L. and Thompson, J. N. (eds) The Genetics and Biology of Drosophila, vol. 3, pp. 105-170. Academic Press, London.

Endler, J. A. 1977. Geographic Variation, Speciation and Clines. Princeton University Press, Princeton, NJ.

HYYTIA, P., CAPY, P., DAVID, J. R. AND SINGH, R. S. 1985. Enzymatic and quantitative variation in European and African populations of Drosophila simulans. Heredity, 54, 209-217.

KINGSOlVER, J. G. AND KOEHL, M. A. R. 1985. Aerodynamics, thermoregulation, and the evolution of insect wings: differ- ential scaling and evolutionary change. Evolution, 39, 488-504.

LATTER, B. D. H. AND ROBERTSON, A. 1962. The effects of inbreeding and artificial selection on reproductive fitness. Genet. Res., 3, 110-138.

LEMEUNIER, F., DAVID, J. R., TSACAS, L. AND ASHBURNER, M. 1986. The melanogaster species group. In: Ashburner, M., Carson, H. L. and Thompson, J. N. (eds) The Genetics and Biology of Drosophila vol. 3, pp. 147-256. Academic Press, London.

LOUIS, J., DAVID, J. R., ROUAUlT, J. AND CAPY, P. 1982. Altitudinal variations of Afro-tropical D. melongaster populations. Dros. Inf. Serv., 58, 100-101.

MISRA, R. K. AND REEVE, E. C. R. 1964. Clines in body dimensions in populations of Drosophila subobscura. Genet. Res., 5, 240-256.

PFRIEM, P. 1983. Latitudinal variation in wing size in Drosophila subobscura and its dependence on polygenes of chromosome O. Genetica, 61, 221-232.

POWELL, J. R. 1974. Temperature related genetic divergence in Drosophila body size. J. Hered., 65, 257-258.

PREVOST1, A. 1955. Geographical variability in quantitative traits in populations of Drosophila subobscura. Cold Spring Harbor Symp. Quant, Biol., 20, 294-299.

REEVE, E. C. R. AND ROBERTSON, F. W. 1953. Studies in quantitative inheritance. II. Analysis of a strain of Drosophila melanogaster selected for long wings. J. Genet., 51, 276-316.

ROBERTSON, F. W. AND REEVE, E. C. R. 1952. Studies in quantitative inheritance. I. The effects of selection on wing and thorax length in Drosophila. J. Genet., 50, 414-448.

SINGH, R. S. 1989. Population genetics and evolution of species related to Drosophila melanogaster. Ann. Rev. Genet., 23, 425-453.

STALKER, H. D. 1980. Chromosome studies in wild populations of D. melanogaster. II. Relationship of inversion frequencies to latitude, season, wing-loading and flight activity. Genetics, 95, 211-223.

STALKER, H. D. AND CARSON, H. L. 1947. Morphological variation in natural populations of Drosophila robusta Sturtevant. Evolution, 1, 237-248.

STALKER, H. D. AND CARSON, H. L. 1948. An altitudinal transect of D. robusta Sturtevant. Evolution, 2, 295-305.

TANTAWY, A. O. AND MALlaH, G. s. 1961. Studies in natural populations of Drosophila. I. Heat resistance and geographical variation in Drosophila melanogaster and $D$. simulans. Evolution, 15, 1-14. 